\title{
Starch Consolidation of Red Clay-based Ceramic Slurry Inside a Pressure-cooking System
}

\author{
Ruben L. Menchavez*, Carl Rhamel M. Adavan, Jamelie M. Calgas
}

\author{
Ceramics and Metallurgical Department, College of Engineering, MSU-Iligan Institute of Technology, \\ Andres Bonifacio Avenue, 9200 Iligan City, Philippines
}

Received: April 9, 2013; Revised: September 2, 2013

\begin{abstract}
The consolidation of red clay-based slurry by gelatinization of starch in a domestic pressure cooker was presented. Aqueous ceramic slurries were prepared consisting of a ternary powder mixture of red clay, quartz, feldspar, and different starch types. The starch slurries with and without the presence of ceramic particles demonstrated the same gelling mechanism and heating time inside the pressure cooker. The gel strengths of pressure-cooked samples were higher than samples heated conventionally. Subsequently, the shaping of large ceramic prototypes is possible using a calculated heating time based on best pressure cooking conditions. The physical characterizations disclosed that the pressure-cooked ceramic samples in dried and fired states exhibited better physical properties depending upon the type of starch added in the ceramic slurry. Specifically, the compressive strengths of fired ceramic bodies shaped in the pressure cooker ranged from $82 \pm 2$ to $255 \pm 9 \mathrm{MPa}$ with bulk porosities of $29.0 \pm 0.8-18.7 \pm 0.2 \%$, whereas the conventionally shaped bodies possessed compressive strengths ranging from $138 \pm 8$ to $164 \pm 11 \mathrm{MPa}$ with bulk porosities of $25.6 \pm 0.1-28.5 \pm 0.2 \%$.
\end{abstract}

Keywords: pressure cooking, starch consolidation, red clay

\section{Introduction}

The starch consolidation technique has been widely explored for shaping ceramic materials through the use of starch loaded in ceramic slurry ${ }^{1,2}$. The insolubility of starch in the ceramic slurry allows the shaping of ceramic green bodies by slip casting into non-porous molds ${ }^{3}$. It is because of this feature that the starch consolidation casting is classified as a direct casting technique, which involves no drainage of water is required to form a desirable ceramic article. This technique has been extensively applied to shaping ceramic powders, such as pure oxide ceramics ${ }^{1-5}$, mullite ${ }^{6,7}$ and cordierite ceramics $^{8,9}$, but that application to clay systems is still quite rare. To the best of our knowledge, the starch consolidation technique was only employed for shaping red clay-based ceramic foam from aqueous slurry consisting of red clay, feldspar and quart $z^{10}$. The main advantage of using starch in ceramic forming, when compared to other biopolymers and natural polysaccharides, is in its chemical purity that secures residual-free during starch burnout ${ }^{1}$. Besides starch is easy to burn-out, it is economically cheap and environmental-friendly technology for implementation in ceramic processing to produce ceramic materials with diverse applications.

The consolidating performance of such starch granule is due to its gelatinization phenomenon involving hydration of amorphous phase and melting of crystalline array ${ }^{6,11}$ at a high temperature $\left(65-80{ }^{\circ} \mathrm{C}\right)$. The starch granule is primarily composed of two polymers such as amylose (linear) and amylopectin (branched) occupying the largest portion $(70-85 \%)^{12}$. The amylose is an amorphous polymer of (1-4)-linked $\alpha$-D-glucopyranosyl units with a molecular

*e-mail: ruben.menchavez@g.msuiit.edu.ph weight that varies depending on the source of the starch but is usually much smaller than that of amylopectin. The amylopectin is a crystalline polymer with short branches having only about $4 \%$ of the D-glucosyl residues, which has molecular weights in the range from about 50 to 100 million Daltons ${ }^{13}$. During the gelatinization of the starch granules at the high temperature, the formation of a starch gel is controlled by the structural interactions of these two polymeric constituents to cause effective hydration swelling ${ }^{14}$. This phenomenon is usually associated with impairment and rearrangement of the intermolecular bonds in the starch granules while heat is applied on the ceramic slurry. This heating effect results in a rapid and irreversible swelling of the starch granules by water uptake that consolidates the ceramic slurry. During a cooling step, the resulting microstructure of the ceramic/starch gel is composed of swollen granules surrounded by ceramic particles that are usually smaller than the starch granules. Subsequently, after drying step, the starch is finally burnout to create pore spaces in the ceramic matrix by heating in an oxidizing atmosphere.

The swollen starch granules formed at elevated temperature have been commonly employed as a sacrificial template for shaping a diverse variety of porous ceramics ${ }^{1-10}$. These diversified porous ceramic materials are made possible with the proper control of the swollen granules as a function of their physical characteristics and chemical compositions. Specifically, the final microstructure of porous ceramics is clearly anticipated by the type, amount, size and morphological feature of the starch granules ${ }^{2-5}$. However, when highly porous ceramics are produced, alteration of the chemical nature of the native starch is required $^{8}$. The starch modification involves the introduction 
of few chemical groups either esters or ethers (e.g., acetates and hydroxypropyl ethers), which create open structures in starch granules to render faster water uptake during gelatinization. As a result, the starch granules largely swell to form highly porous ceramics as compared to its native form. An additional advantage of starch modification is the gelatinization of starch granules at a lower temperature, which is due to the weakening of hydrogen bonding in starch under strong interference of chemical substituents to the starch molecules ${ }^{8}$.

Despite of the competitive advantages of using starch in the production of porous ceramics, some ceramic processing issues are encountered, such as different gelatinization temperature, long heating time ${ }^{6}$, segregation and sedimentation of particles ${ }^{8}$, and others. Particularly, it takes at least one hour to reach the gelatinization temperature of the starch in the ceramic suspension as manifested by the increased in the slurry viscosity. This heating problem is aggravated with the use of a large volume of ceramic slurry to be heated as it is influenced by the thermal gradient ${ }^{6}$ of the ceramic slurry. Also, the solidification time of ceramic slurry increases as the starch amount added is reduced at which the available starch granules that absorb the excess water are significantly diminished. A long heating time (at least three hours) is required to consolidate the ceramic slurry through partial drying to reduce the available liquid. Moreover, the long heating time causes unavoidable sedimentation of both ceramic and starch particles before the onset of gelatinization due to a large density variation between the suspended particles and the dispersing medium. These heating issues of ceramic slurry seriously cause inhomogeneous gelatinization of starch granules and density gradients in particle compact, which ultimately develop forming problems such as stress and crack during drying and sintering of the ceramic compact. To circumvent these forming limitations, a fast heating rate is employed to prevent particle sedimentation, and the heating temperature is set higher than the pasting temperature of starch granules to ensure complete gelatinization. However, at normal atmospheric conditions, the increase in temperature above the pasting temperature results in faster evaporation and boiling of liquid, which cause the cast ceramic slurry useless for further processing. Hence, to realize the high temperature heating, the pressure of the liquid in the ceramic slurry is intentionally increased so that the boiling point of liquid is increased above $100{ }^{\circ} \mathrm{C}^{[15]}$.

The elevation of boiling point of liquid under elevated pressure can be conveniently achieved in a sealed vessel known as the pressure cooker ${ }^{16}$. It is commonly used for cooking food faster than conventional cooking methods, which presents a significant saving of energy. The heating sequence taking place inside the pressure cooker involves three successive events ${ }^{17}$. The first and second periods involve heating of liquid and elevation of interior pressure due to rise in temperature and water vaporization. In this period, the heating is maintained to cook the products at a desired time with simultaneous generation of pressurized steam. The pressure of steam was regulated by a valve associated with the designed pressure of the pressure cooker. Immediately after this event, the third period starts after shutting down the heat source. The pressure starts to fall to the atmospheric level during this so-called decompression phase. In this final stage, different phenomena occur simultaneously or successively, such as conduction, free convection, evaporation, condensation, and others.

The merits of the pressure cooking method have been reported to be applicable in some material processing methods. Ming et al. ${ }^{18}$ employed a pressure cooker to render rapid polymerization of a polymethyl methacrylate polymer. They found out that the polymerized product had a lower porosity than the conventional counterpart due to the role of the pressure, which accelerated the polymerization and prevented boiling of the polymer solution. Undurwade and Sidhaye ${ }^{19}$ studied the processing of a heat-cured polymethylmethacrylate denture base resin in a pressure cooker. The polymerized denture had a high flexural strength due to the reduction of residual monomer and porosities. Moreover, a fast curing acrylic resin was achieved well below an elevated boiling point of monomer without a tendency to boil due to a clamped denture flask under a sufficient pressure ${ }^{20}$.

The application of the pressure cooking technology to ceramic processing involving the starch consolidation technique has not yet been reported so far in the ceramic literatures. The pressure cooking technique is expected to offer some advantages to ceramic processing, such as short heating time, energy saving, and high processing temperature. Hence, the present study demonstrates the application of pressure cooking technology to consolidating red clay-based ceramic slurry through gelatinization of starch inside a domestic pressure cooker as a fast shaping technique. This study presents not only new avenue with respect to the combination of high heat and pressure for processing of ceramic slurry, but also the first to apply starch consolidation to red clay-based systems using the pressure cooking technology. This study focuses on the shaping of red clay-based materials from ceramic suspensions individually loaded with different starch types inside the pressure cooking system. Specifically, the study has threefold aims: (i) to determine the gelatinization time of different starches with and without the presence of ceramic particles in terms of gel strength, (ii) to compare the physical properties of ceramic bodies shaped by the pressure-cooked consolidation to the conventional starch consolidation, and (iii) to compare the microstructure of the fired samples formed by pressurecooked consolidation and conventional starch consolidation techniques.

\section{Material and Experimental Procedures}

\subsection{Raw material}

The red clay used as plastic material was mined in lumped form from Lama-Lama, Tubod, Lanao del Norte, Philippines. The non-plastic materials such as feldspar and quartz were commercially available with average particle sizes (LS 100Q, Coulter Corporation) of 35.1, and 27.0 $\mu \mathrm{m}$, respectively. Correspondingly, the chemical composition of the ceramic raw materials was given in Table 1 . These powdered materials were dispersed in distilled water 
Table 1. Chemical composition of the raw materials.

\begin{tabular}{lcccccccc}
\hline \multirow{2}{*}{ Materials } & \multicolumn{8}{c}{ Oxide contents } \\
\cline { 2 - 9 } & $\mathbf{S i O}_{2}$ & $\mathbf{A l}_{2} \mathbf{O}_{3}$ & $\mathbf{F e}_{2} \mathbf{O}_{3}$ & $\mathbf{M g O}$ & $\mathbf{C a O}$ & $\mathbf{N a}_{2} \mathbf{O}$ & $\mathbf{K}_{2} \mathbf{O}$ & l.o.i. \\
\hline Red clay & 41.6 & 25.2 & 8.2 & 1.1 & 0.5 & 0.5 & 0.5 & 22.4 \\
Quartz & 95.1 & 1.7 & 0.4 & 1.4 & 0.5 & 0.1 & 0.3 & 0.6 \\
Feldspar & 66.3 & 21.5 & 0.3 & 0.5 & 2.4 & 8.5 & 0.1 & 0.4 \\
\hline
\end{tabular}

with the aid of a sodium tripolyphosphate (STPP) as the dispersing agent. The non-plastic materials and dispersant were supplied by Elmar Marketing, Mindanao, Philippines. Different types of commercially available starches, namely, corn, potato, and cassava, were used as solidifying agents with an average particle size of 12.1, 40.9, and 18.7 microns, respectively. Cylindrical mold cavities (dimensions: Diameter $=3 \mathrm{~cm}$, Height $=5 \mathrm{~cm}$ ) were assembled using acetate film joined by a double-sided tape.

\subsection{Preparation of red clay-based ceramic slurry loaded with starch}

The red clay-based ceramic slurry without starch was firstly prepared in a cylindrical polyethylene container filled with dispersant solution $(0.7 \mathrm{wt} \%$ based on the mass of ternary mixture) and alumina balls at a mass equal to a ternary mixture. The ternary mixture consisted of $46.7 \mathrm{wt} \%$ red clay, $35.3 \mathrm{wt} \%$ feldspar and $18.0 \mathrm{wt} \%$ quartz, which was based on standard stoneware formulation ${ }^{21}$. After the dispersing solution had been prepared, the red clay was added. Since it is in lumped state, the clay was initially dried in a conventional oven for four hours at $110^{\circ} \mathrm{C}$ to thoroughly remove the moisture. The dried clay was crushed to reduce its lumped size in a pulverizer and loaded to the dispersing solution. The clay-water mixture was milled for four hours, and after which it was added with the desired masses of quartz and feldspar powders. All additions of ceramic powders were based on a target solid loading of about $70 \%$ ceramic solids in the slurry. Subsequently, additional milling of four hours was conducted to effectively disperse the ceramic particles at a mill speed of 55 revolutions per minute.

The prepared ceramic slurry of $70 \%$ solid loading was divided into three equal parts. Each part was loaded with $16 \mathrm{wt} \%$ starch based on the mass of ternary powder. The starches added were corn, potato, and cassava, respectively. An additional milling step was employed to homogenize the ceramic-starch slurry for about four hours. After this milling step, the alumina balls were screened, and the ceramic slurry was sieved to remove large agglomerates through a 70 mesh screen. Correspondingly, the rheological data of the ceramic slurries loaded with and without the starch powder were then immediately collected using a viscometer (RVDE 230, Brookfield Engineering Laboratories, Inc.). The measurements were conducted at varying spindle speeds of 10, 20, 30, 50, 60 and 100 revolutions per minute. Subsequently, the flow curves of the starch-loaded ceramic slurries were reported in terms of viscosity against varying shear rate.

\subsection{Pressure cooking parameters of starch slurry with/without ceramic particles}

To determine the pressure cooking time of starch slurry without ceramic particles, each of the three starches was separately prepared in slurry of $25 \mathrm{wt} \%$ powder mixed manually with $75 \mathrm{wt} \%$ water for about three minutes. The starch slurry was poured into cylindrical molds in three replicates, which were covered with acetate film to prevent immature drying of the slurry during heating. The slurryfilled molds were respectively placed into $250 \mathrm{~mL}$ beakers and then put inside a pressure cooker (Moulinex pressure cooker classic made in France, 6.0 liters) equipped with a control valve to regulate excessive build up of pressure during heating. According to a user manual, the pressure cooker has a maximum pressure of $15 \mathrm{psi}(103 \mathrm{kPa})$ above atmospheric pressure that allows water temperature to reach up to $121^{\circ} \mathrm{C}\left(250^{\circ} \mathrm{F}\right)$ during heating. The cylindrical chamber of the pressure cooker was initially filled up with $600 \mathrm{~mL}$ distilled water so that only halfway of the beaker height was submerged. This setup allowed only heating of the ceramic slurry through the generated steam under high pressure. The pressure cooker was then placed on top of a hot plate (Nouva II, SYBRON Thermolyn Corporation) as the heat source with maximum setting. When the whistling sound was firstly heard from the pressure cooker, the heating time was started and held at variations of 9, 12, and 15 minutes. After this heating scheme, the pressure cooker was removed and cooled with running water for about ten minutes to reduce the inside temperature. Finally, the pressure cooker was opened, and the solidified samples were further cooled to room condition.

In finding the pressure cooking time of starch slurry with ceramic particles, the starch-loaded ceramic slurries described in section 2.2 were used and processed with exactly the same procedures from casting to pressure cooking of the pure starch slurry. For a comparative evaluation, similar starch slurries with and without ceramic particles were cast into three replicates of cylindrical molds and heated conventionally inside an oven for three hours at $80{ }^{\circ} \mathrm{C}$. After this heating step, the gelled samples with and without ceramic particles were cooled for about two hours. Immediately after cooling, the gel strengths were measured using an unconfined compression apparatus (Marui \& CQ., LTD., Osaka, Japan) equipped with $5 \mathrm{~mm}$ circular plunger. The plunger was allowed to penetrate to the gelled sample until a depth of $10 \mathrm{~mm}$ and the loading force was noted. The gel strengths were then computed as the force divided by the cross-sectional area of the plunger, and the average of three measurements was reported. Subsequently, the cooking time 
that provided the highest gel strength was selected as the best heating time inside the pressure cooker.

\subsection{Drying and high temperature treatment of the gelled ceramic bodies}

The gelled ceramic bodies were demolded and wrapped with a wet paper to avoid drying cracks at room conditions for one week. The naturally dried samples were further oven dried at temperatures between 50 and $110^{\circ} \mathrm{C}$ until reaching a constant weight. TG/DTA analyses (Thermo plus, TG 8120, Rigaku, Japan) were then carried out inorder to gain insight into the decomposition behavior of starch paste in the red clay-based composite. A dried powder was prepared and heated until $1000{ }^{\circ} \mathrm{C}$ at a rate of $10{ }^{\circ} \mathrm{C} / \mathrm{min}$ under a constant flow of synthetic air at $100 \mathrm{~mL} / \mathrm{min}$. Moreover, the dried samples were polished (Leco VP-50, Leco Corporation) into symmetric cylindrical shapes. The polished samples were then fired in an electric muffle furnace (Vecstar furnaces) to a firing temperature of $1250{ }^{\circ} \mathrm{C}$. The firing schedules were decided based on outcomes of the thermogravimetric analyses of dried samples as described in section 3.4. The heating was commenced until $100^{\circ} \mathrm{C}$ with one hour soaking, and the temperature was then increased up to $300{ }^{\circ} \mathrm{C}$ with two hours soaking. The temperature was further increased up to $500{ }^{\circ} \mathrm{C}, 800^{\circ} \mathrm{C}$, and $1100^{\circ} \mathrm{C}$, with one hour soaking at each temperature to avoid firing cracks. The heating rate of $10{ }^{\circ} \mathrm{C} / \mathrm{min}$ was employed for any desired temperature. Finally, upon reaching the temperature of $1250{ }^{\circ} \mathrm{C}$, the soaking was two hours and the furnace was naturally cooled.

\subsection{Physical characterizations}

The dried and fired shrinkage was determined by measuring the initial and final heights of the green and the fired cylindrical samples with the use of a vernier caliper. The shrinkage was then calculated as initial height minus final height divided by the initial height. The dried bulk porosity was determined on polished cylindrical samples (green body). The dried bulk porosity was then calculated as one minus bulk density of the sample divided by an equivalent powder density of the sample determined by the pycnometer method. The bulk density was determined by weighing the cylindrical sample divided by the calculated bulk volume of cylindrical sample through measured dimensions. Finally, all results were multiplied by $100 \%$ and the average of three measurements was reported.

The porosity of fired cylindrical samples was determined by boiling the ceramic sample in water-filled container for four hours. After the boiling step, the fired samples were naturally cooled for 24 hours in water before weighing. The apparent porosity was calculated using Equation 1.

$\% \mathrm{AP}=[(\mathrm{I}-\mathrm{F}) /(\mathrm{I}-\mathrm{S})] \times 100 \%$

where $\% \mathrm{AP}$ is apparent porosity, I is the weight of the soaked sample after boiling, $\mathrm{F}$ is the weight of fired sample before immersion, and $\mathrm{S}$ is the suspended weight of the sample while it was submerged in water.

To determine the compressive strength, both the dried and fired cylindrical samples were compressed on a versa-loader machine (Model G-900-4, ELE International,
SOILTEST Products Division). The breaking force, $\mathrm{y}$ in unit kgf, was determined using an Equation 2.

$y=4.466171 x-25.061$

where $\mathrm{x}$ is the dial reading on the machine multiplied by 10 divisions. The compressive strength (in MPa) was then calculated as the breaking force divided by the crosssectional area of the cylindrical sample. Subsequently, the average of three measurements was reported.

The microstructural features of the fired ceramic samples consolidated inside the pressure cooker were compared to the ceramic samples shaped in the conventional oven. The sintered samples were sliced into $3 \mathrm{~mm}$ thickness, using a crystal cutter equipped with a circular blade having a diamond-coated edge (Maruto Instrument Co., LTD., Japan). The sliced surfaces of the sintered samples were directly observed on a 3D measuring laser microscope (LEXT OLS4000, Olympus) at 20 and 50 magnifications. The pores left by the starch particles in the samples during thermal treatment were characterized with the available image processing software (Image pro plus). Although the morphologies of pores left by the starch were irregular, their diameters were approximately determined by a circular fitting. Finally, a statistical evaluation was employed to determine the distribution of pore sizes in terms of an average pore diameter for each class size against pore frequency. The pore frequency is the number of measured pore diameters falling for each designed class size of diameters.

\section{Results and Discussion}

\subsection{Gel strength of different types of starches}

Table 2 shows the gel strengths of the different starches heated at varying time inside the pressure cooker and heated conventionally in an oven. It can be observed that the gel strengths of different types of starches heated inside the pressure cooker are significantly higher than that of gels heated in the oven. This higher gel strength can be attributed to a formation of highly swollen starch granules in the pressure cooker than in the conventional oven. These swollen granules absorb more water than their conventional counterpart, making the gel more rigid upon cooling. During the gelatinization step inside the pressure cooker, it is believed that the amylose-lipid complex in the starch granules being broken by heating under the combination of high heat and pressure ${ }^{22}$. Then, the disorganized amylose molecules might align themselves or associate with each other and form a rigid gel upon cooling,

Table 2. The average gel strengths $\left(\mathrm{kN} / \mathrm{m}^{2}\right)$ of pure starches subjected to heating conditions.

\begin{tabular}{lcccc}
\hline \multirow{2}{*}{$\begin{array}{c}\text { Starch } \\
\text { types }\end{array}$} & $\begin{array}{c}\text { Conventional } \\
\text { heating }\end{array}$ & \multicolumn{2}{c}{ Pressure cooking time, (minutes) } \\
\cline { 3 - 5 } & & $\mathbf{9}$ & $\mathbf{1 2}$ & $\mathbf{1 5}$ \\
\hline Cassava & 60.7 & 98.3 & 113.4 & 75.5 \\
Corn & 48.2 & 290.1 & 336.0 & 288.6 \\
Potato & 64.2 & 138.0 & 232.7 & 165.8 \\
\hline
\end{tabular}


known as retrogradation ${ }^{23}$. It is, therefore, postulated that this mechanism for the development of gel strength is not dominating in the conventionally heated gels.

It is also noticeable that, in pressure-cooked starches, the trend of gel strengths is increasing until maximum and then decreasing with prolonged cooking time. The trend of such gel strengths observed after pressure cooking is similar to heating of starch in a conventional manner as reported in literatures ${ }^{24,25}$. Before the optimum gelation or dissolution time is reached, the starch granules are slightly swollen and highly intact ${ }^{22}$. The slurry of such starch would be low in viscosity and physically has poor clarity in appearance. According to literatures ${ }^{24,26}$, the gel strength of the starch gel is dependent upon the viscosity of heated starch, chemical composition, structures, and heating parameters. Hence, to improve the physical characteristics of the gel it is desirable to increase the cooking time and temperature. At the optimum pressure cooking time, majority (approximately $80 \%$ ) of the starch granules are highly swollen with only small percentages (about 10\%) of uncooked and ruptured granules ${ }^{27}$. In the case of pressure-cooked starch granules, it is believed that the granules were completely swollen due to the high temperature heating (about $120{ }^{\circ} \mathrm{C}$ ). The crystalline nature of starch is thermally disrupted to render desirable characteristics including maximum viscosity, good clarity, and high gel strength. If the starch granules are heated longer than the optimum time, the majority of the granules are ruptured with a large percentage of fragments ${ }^{28}$. During this overheating condition, the soluble component of the starch granules are leached out including water, causing serious deformation and rupture. This granule deformation was visually confirmed by scanning electron microscopy as reported by Jing-ming and Sen-lin ${ }^{29}$ for the morphological changes of starch granules from potato and corn. They found out that, at high temperature, the starch granules further swell and melt, which ultimately the molten granules connected with each other to form a spongelike structure. In a specific case when a starch is subjected to a high temperature heating with prolonged time under high pressure, the starch granules appear to be like mud like structure $^{22,28}$. The gels formed from such highly deformed starched granules can still exhibit good gel clarity, but it is less cohesive and usually lower in viscosity than the gel subjected to the optimum heating conditions. Therefore, either undercooked or overcooked starch may lead to poor functionality.

Interestingly, regardless of the starch types used in this study, the pressure cooking time of 12 minutes presents the highest gel strength. Therefore, it can be deduced that the best gelatinization time of any starches investigated is 12 minutes under the pressure cooking method. The order of pressure-cooked gel strengths follows in a decreasing order as corn $>$ potato $>$ cassava. In contrast, the gel strengths of samples heated conventionally follow in a decreasing order as potato $>$ cassava $>$ corn. This observed trend of gel strengths could be attributed to the polymeric structures and chemical composition of starch granules ${ }^{26}$, which influence the granular swelling to cause gelatinization. It is worthwhile to note that the polymeric structure is mainly composed of amylose and amylopectin. The amylose is a linear molecule containing lipids, whereas the amylopectin is a branched polymer associated with phosphate groups. The swelling ability of starch is represented by increasing content of amylopectin enhanced by the presence of phosphate groups. The repulsion between phosphate groups on adjacent chains will increase water hydration by weakening the extent of bonding within the crystalline domain of granules. According to published literatures ${ }^{26,30}$, the decreasing content of amylopectin for different types of starch follows in a sequence of cassava, potato, and corn. However, in this study, the potato gel exhibited the highest gel strength that may be due to a lower concentration of lipids. The presence of lipids in starch may have a reducing effect on the swelling of individual granules by the formation of amylose-lipid complexes ${ }^{31}$ during the heating process. This mechanism probably explains why the gel strength of cassava is lower than potato. In the case of corn starch, the lowest measured gel strength is attributable to the lowest content of amylopectin with a high amount of lipids that inhibit granule swelling. Thus, the poor granule swelling leads to poor gel strength.

For the gel strengths of pressure-cooked samples, the opposite trend is observed as compared to samples heated conventionally. The corn starch gel has the highest gel strength as compared to cassava and potato gel. This could be attributed to a lesser tendency of the corn starch grains to rupture during swelling at high temperature and pressure, owing to a lower rate of leaching effect on amylose polymer. It is pointed out that the higher fraction of ruptured grains is the lower the gel strength ${ }^{31,32}$. The lowest gel strength for cassava is may be due to the highest content of amylopectin. A long chain structure of the amylopectin could make it sensitive to bursting during pressure cooking. Subsequently, a high fraction of granule rupture or bursting resulted in molecular fragmentation ${ }^{29}$ that eventually caused a significant reduction of the gel strength. Since the corn and potato starches exhibited the higher gel strengths than the cassava starch, these two starches were selected for further comparative evaluation as described in the next sections.

\subsection{Rheological behavior of the starch-loaded ceramic slurry at room conditions}

The flow curves of the ceramic slurries loaded with corn and potato were observed at varying shear rates as shown in Figure 1. It can be observed that all slurries exhibited a decreasing viscosity as the shear rate increases. This slurry property is typical of shear thinning behavior suitable for further slip casting process. Interestingly, both slurries added with starches maintained the shear thinning behavior when compared to ceramic slurry alone. The shear thinning behavior can be illustrated according to the arrangement of ceramic particles in suspension. During near equilibrium of ceramic suspension, random collisions among particles make them naturally resistant to flow leading to high observed viscosity. However, as the shear stress increases, the particles become organized in a streamlined structure with the flow, which ultimately lowers their viscosity ${ }^{33}$.

The viscosities of ceramic slurries loaded with and without starches are shown as a function of increasing shear rates in Figure 1. It is evident that the viscosity of starch- 
loaded ceramic slurry is higher than that without starch addition. The rise in viscosity can be primarily explained through mineral composition of the ceramic powders used and the surface charge developed after dispersion. Also, secondary factors causing the increase in viscosity are the reduction of the available liquid for dispersion due to the addition of starch granules and the associated liquid wetting on the surface of starch granules. The mineral composition of the red clay according to a previous study ${ }^{34}$ is composed of montmorillonite, hematite, and alkali/ alkaline bearing minerals with minor free quartz. During dispersion of these minerals in water, the tripolyphosphate anions are believed to adsorb on the positive edge of clay platelets that make the red clay particles highly negative ${ }^{35}$. On the other hand, the negatively charged dispersant adsorbs on positive sites of minerals, such as feldspar and quartz, and their associated powders ${ }^{36}$. Hence, all surfaces of the ternary powder used in this study possibly are negative or basic after dispersion in water. Since the starch granules are reported to behave acidic or positively charged, the adsorption of such granules onto the ceramic particles is very likely ${ }^{36}$. This starch adsorption causes an inevitable formation of large particle clusters that hinder the flow of particles past each other leading to the increased viscosity. In fact, there is a large increase in viscosity for ceramic slurry loaded with corn starch as compared to ceramic slurry alone shown in Figure 1. The observed viscosity is aggravated when potato starch was loaded to ceramic slurry. It is believed that the highest viscosity of potato-loaded ceramic slurry was probably due to the polymeric constituents of starch as described in section 3.1. It is reported that the potato starch has a higher content of amylopectin polymer than that of corn starch, which has a strong tendency to attach on basic surfaces ${ }^{37}$. Thus, when potato starch is mixed with the ceramic suspension, a higher fraction of particle clusters could be developed causing the rise in viscosity. Despite of the increase in viscosity of ceramic slurry due to the starch addition, the flowability and castability are still applicable for subsequent slurry processing.

\subsection{Gel strength of the starch slurry in the presence of ceramic particles}

Table 3 shows the different gel strengths of the starchloaded ceramic bodies heated in the pressure cooker and the conventional oven. It can be observed that the trend of gel strengths is the same as in the pure starch gels heated inside the pressure cooker. This indicates that the mechanism of swelling or gelatinization of starch granules under pressure cooking is the same in the presence of ceramic particles. Moreover, the measured gel strengths of the pressurecooked samples indicate that the pressure cooking method is effective in producing highly swollen granules as compared with the conventional method. For conventionally heated ceramic slurry with starch, the gel strength is higher with potato than with corn. This difference in gel strengths for the two starches is maybe due to the variation in their polymeric constituents, among other factors. This observation agrees with the measured gel strengths of the pure starches heated conventionally.

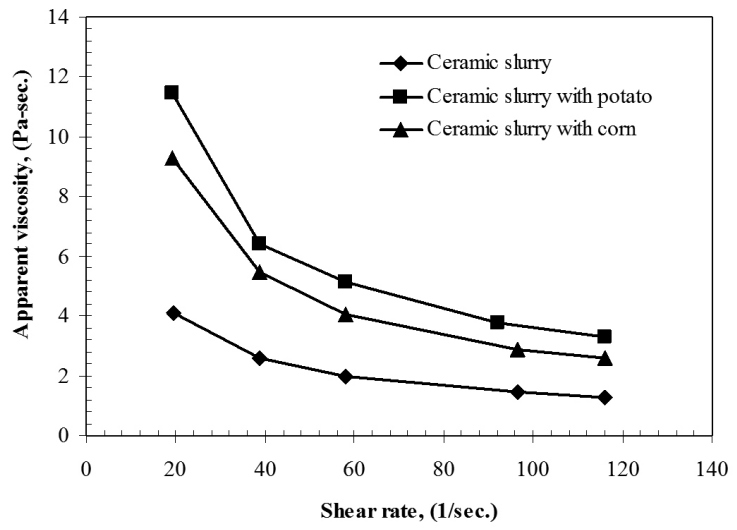

Figure 1. Comparison of the viscosity versus shear rate of the ceramic slurries loaded with different starches.

Table 3. The average gel strengths $\left(\mathrm{kN} / \mathrm{m}^{2}\right)$ of starch slurry with ceramic particles subjected to heating conditions.

\begin{tabular}{llccc}
\hline \multirow{2}{*}{$\begin{array}{c}\text { Ceramic slurry } \\
\text { loaded with }\end{array}$} & $\begin{array}{c}\text { Conventional } \\
\text { heating }\end{array}$ & \multicolumn{3}{c}{$\begin{array}{c}\text { Pressure cooking time, } \\
\text { (minutes) }\end{array}$} \\
\cline { 3 - 5 } & & $\mathbf{9}$ & $\mathbf{1 2}$ & $\mathbf{1 5}$ \\
\hline Corn & 96.2 & 172.7 & 219.6 & 185.0 \\
Potato & 156.9 & 190.0 & 202.8 & 190.0 \\
\hline
\end{tabular}

It is also consistent that the pressure-cooked ceramic bodies exhibited higher gel strengths at any pressure cooking time than the ceramic bodies heated conventionally. At the undercooked pressure cooking time, the gel strength for ceramic body with corn starch is lower than that for ceramic body with potato starch. This is maybe because the corn starch exhibited partial swelling of the starch granules due to poor water absorption of the polymeric structures at short heating time. The partial granule swelling is caused by the insufficient heat applied due to short heating time coupled with the thermal gradient in the bulk ceramic slurry. However, for potato starch in the ceramic slurry, it is believed that the fraction of swollen granules is higher than that of the corn starch due to their high amylopectin content ${ }^{31}$. At overcooked pressure cooking time, the gel strengths of ceramic samples loaded with potato and corn starches are reasonably equal because there is enough heat for the starch granules to swell and rupture. Nevertheless, the best gelatinization time for ceramic bodies containing any of the starches is reasonably about 12 minutes.

\subsection{Thermal decomposition of gelatinized starch in the red clay-based composite}

The thermal oxidative degradation of the gelatinized starch under atmospheric conditions provides practical information in establishing an appropriate heating scheme for the red clay-based compacts. Figure 2a shows the thermogravimetric analyses of the dried red clay-based compacts consolidated with potato and corn starches inside the pressure cooker. It can be clearly seen that the weight loss profiles are similar for the two compacts studied, which is the resultant weight losses of the starch and the red clay 
components in the composite mixture. These decomposition profiles are similar to previous studies on native starches and montmorillonitic clays ${ }^{38,39}$. It should be noted that the pressure cooking of starch-loaded ceramic mixture did not alter the thermal decomposition behavior of the gelatinized starch. Based on the minimum in the differential weight loss shown as an inset on Figure 2a, the thermal decomposition mechanism of starch consolidated compact can be reasonably divided into three thermal events. The first thermal event happens between the room temperature and $140{ }^{\circ} \mathrm{C}$, which corresponds to an endothermic peak shown in Figure $2 \mathrm{~b}$ at about $51{ }^{\circ} \mathrm{C}$. It represents physical dehydration of absorbed and abounded water in the gelatinized starch
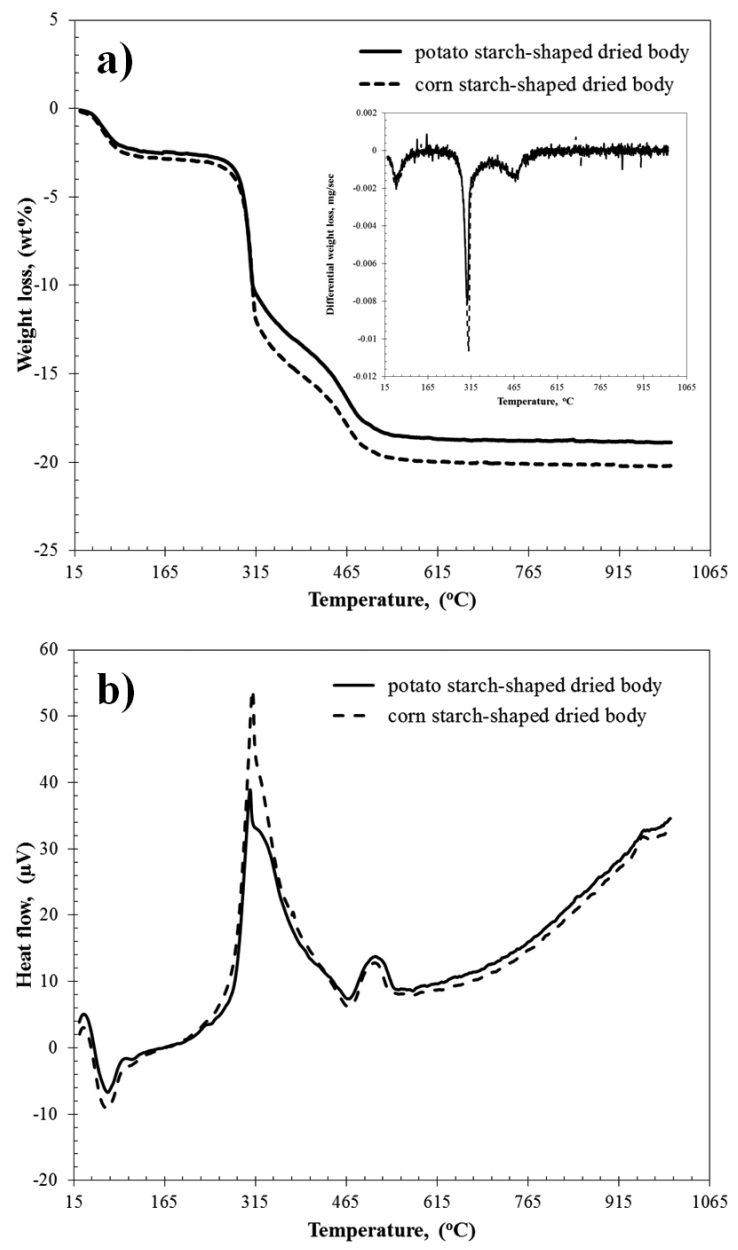

Figure 2. Thermographs of dried red clay-based ceramics consolidated with different starches: (a) thermogravimetric mass loss profiles, and (b) differential thermal analysis curves. and red clay ${ }^{39,40}$. Upon further heating, the second thermal event is encountered between $190{ }^{\circ} \mathrm{C}$ and $375{ }^{\circ} \mathrm{C}$. This can be considered as the main degradation zone for the starch-based ceramic composite, which is represented by a strong exothermic peak at around $303{ }^{\circ} \mathrm{C}$ on Figure $2 \mathrm{~b}$. Some studies ${ }^{38,40,41}$ explained that, within this temperature range, a thermal condensation is taking place between hydroxyl groups of starch chains to form ether segments with associated liberation of water molecules and other molecular species. Also, dehydration of neighboring hydroxyl groups in the glucose ring occurred, resulting in the formation of $\mathrm{C}-\mathrm{C}$ bonds or breakdown of the glucose ring. In the case of the red clay component, volatile specie evolves in the form of water molecules bounded to the exchangeable cations in the interlayer space of montmorillonite phase of the red clay ${ }^{39}$. Finally, the third thermal event happens between $380^{\circ} \mathrm{C}$ and $565^{\circ} \mathrm{C}$. It corresponds to a weak exothermic peak at about $472{ }^{\circ} \mathrm{C}$ in Figure $2 \mathrm{~b}$. This last thermal event is attributed to the oxidation of partially decomposed $\operatorname{starch}^{38}$. Moreover, it is also contributed by the dehydroxylation of the structural water of the red clay as an exothermic reaction event ${ }^{39}$.

\subsection{Physical characteristics of the dried and fired ceramic bodies}

The physical characteristics of dried ceramic samples with the gelled starches are listed in Table 4. It can be observed that the linear shrinkage of ceramic samples shaped with cornstarch inside the pressure cooker is higher than the same samples shaped inside the conventional oven. The high linear shrinkage results in a lower porosity that indicates more compact particles. It can be related to the production of some fragmented starch granules during pressure cooking ${ }^{22,27}$, which filled up available interstices between particles to give the more compact structure during drying. This means that the higher the compact porosity the lower the shrinkage since the contact area between particles is lower. Hence, the conventional sample is more porous because it was though that the starch granules were swollen with minimal fragmentation during heating, thereby generating more interstices as the ceramic particles compacted around the swollen starch granules. In fact, the strength is about fourfold lower than the pressure-cooked sample using corn starch. In contrast, as listed in Table 4, the dried linear shrinkage is higher for conventionally shaped sample using potato starch than pressured-cooked samples. This can be explained according to the higher swelling ability of the potato starch granules to cause the gelation of ceramic slurry inside the pressure cooker. During drying of such gelled ceramics, a lower dried shrinkage is observed due to the swollen granules that shrink largely to leave more empty spaces between the ceramic particles.

Table 4. Physical characteristics of the dried ceramic bodies containing starch.

\begin{tabular}{lcccc}
\hline \multirow{2}{*}{ Physical properties } & \multicolumn{2}{c}{ Ceramic bodies with corn starch } & \multicolumn{2}{c}{ Ceramic bodies with potato starch } \\
\cline { 2 - 5 } & Conventionally heated & Pressure cooked & Conventionally heated & Pressure cooked \\
\hline Linear shrinkage (\%) & $13.3 \pm 0.1$ & $15.6 \pm 0.5$ & $13.4 \pm 0.6$ & $12.2 \pm 0.2$ \\
Total porosity (\%) & $57.2 \pm 1.0$ & $49.2 \pm 2.5$ & $47.7 \pm 1.4$ & $49.7 \pm 2.3$ \\
Compressive strength (MPa) & $10 \pm 1$ & $46 \pm 6$ & $79 \pm 8$ & $55 \pm 8$ \\
\hline
\end{tabular}


This results in a more open compact of dried ceramic gel as corroborated with the higher bulk porosity. Correspondingly, the dried compressive strength of potato-shaped ceramic sample shaped inside the pressure cooker is lower than the conventional counterpart. Also, the dried shrinkage was higher for potato-shaped ceramic sample heated conventionally due to a more compact structure.

Table 5 lists the physical properties of fired ceramics shaped with potato and corn starches. The linear shrinkage of samples shaped inside the pressure cooker using corn starch is higher than the samples heated conventionally in the oven. This is because the grain sintering by thermal action leads to a better densification of the pressure-cooked compact using the corn starch. This is corroborated with a lower porosity as compared with the fired sample shaped conventionally. Correspondingly, the fired compressive strength of pressure-cooked sample reaches as high as $255 \pm 9 \mathrm{MPa}$ when compared to conventional counterpart of about $138 \pm 8 \mathrm{MPa}$. The difference in compressive strength of both sintered samples is due to a higher porosity of about $25.6 \pm 0.1 \%$ for conventionally consolidated sample than pressure-cooked sample of about $18.7 \pm 0.2 \%$. This implies that, when the porosity is increased, the compressive strength normally decreases.

The linear shrinkage of fired samples shaped with potato inside the pressure cooker is lower than conventional counterpart due to the higher porosity of the dried compact. This is supported with the higher porosity of such sample than the conventional sample. This corresponds to a lower compressive strength of $82 \pm 2 \mathrm{MPa}$ for the pressurecooked sample than the conventional sample having about $164 \pm 11 \mathrm{MPa}$. Therefore, the observed physical data of the fired ceramics imply that their physical characteristics depend on the type of starch used during shaping inside the pressure cooker.

\subsection{Microstructure of the fired red clay-based ceramics}

It was shown above that, regardless of the heating conditions, the compressive strength of fired ceramic samples shaped with potato starch is lower than that of ceramic samples consolidated with the corn starch. This can be related to the difference in the porous characteristics of both sintered samples. Hence, the microstructures of the fired ceramic bodies consolidated inside the pressure cooker were optically observed and compared as depicted in Figure 3. It is worthwhile to point out that the microstructures of samples shaped inside the oven and the pressure cooker revealed no recognizable difference in microstructural features. However, image analyses of the microstructures revealed a difference in pore sizes that coincided with the measured compressive strength of the sintered samples. The micrographs for sample shaped with corn starch in the conventional oven exhibited an average pore diameter of about 16.0 microns with maximum pore diameter of 37.3 microns. As listed on Table 5, these pore diameters are large enough to lower the strength of sintered samples shaped inside the oven than that of samples shaped inside the pressure cooker. In the case of ceramic sample shaped with potato starch inside the oven, an average pore diameter of 48.4 microns with maximum pore diameter of 116.3 microns was measured. These pore diameters are lower than the samples shaped inside the pressure cooker as mentioned below, and hence the compressive strength is correspondingly higher than the pressure-cooked counterpart (Table 5).

Both optical micrographs in Figure 3 show smaller pores that correspond to the connecting contact areas between larger pores. It is evident that the overall pore structures are consisted of irregularly large-shaped pores associated with a few fractions of rounded pores left by the starch particles. These observed pore morphologies of both sintered samples are similar to the findings reported in the literature involving starch as the forming agents ${ }^{5,6}$. The presence of irregular pore morphology may support the postulated fragmentation of swollen starch granules during the heating inside the pressure cooker. Comparing the micrographs of Figure $3 \mathrm{a}$ and Figure 3b, the sintered sample shaped with corn starch clearly revealed small pores as compared with sintered sample consolidated with the potato starch. At the same magnification used during the optical observation, few large pores having an average diameter of about 51.8 microns are observable for samples shaped with potato starch, whereas many small pores having an average diameter of about 14.2 microns are clearly visible for sample consolidated with corn starch. Correspondingly, the distribution of average pore diameters versus frequency is shown in Figure 4. It can be seen that both sintered samples showed a bimodal distribution of pore diameters. The first peaks in the pore distributions for the two samples depicted the higher frequency of pore sizes that are closer to the average particle sizes of both starches. Moreover, the sintered sample shaped with corn starch has the maximum pore diameter of about 29.0 microns, whereas the sintered sample consolidated with potato starch has the maximum pore diameter as high as 132.0 microns. It can also be observed that the solid struts surrounding the pores for both fired samples are intact without noticeable firing cracks. It is worthwhile to note that the solid struts contribute to the strength of the sintered compacts, whereas the pores cause weaknesses during mechanical support. The large difference

Table 5. Physical characteristics of the fired ceramic bodies shaped with different starches.

\begin{tabular}{lcccc}
\hline \multirow{2}{*}{ Physical properties } & \multicolumn{2}{c}{ Corn starch-shaped ceramic body } & \multicolumn{2}{c}{ Potato starch-shaped ceramic body } \\
\cline { 2 - 5 } & Conventionally shaped & Pressure shaped & Conventionally shaped & Pressure shaped \\
\hline Linear shrinkage (\%) & $12.0 \pm 0.4$ & $13.2 \pm 0.6$ & $13.9 \pm 0.4$ & $12.0 \pm 0.5$ \\
Total porosity (\%) & $25.6 \pm 0.1$ & $18.7 \pm 0.2$ & $28.5 \pm 0.2$ & $29.0 \pm 0.8$ \\
Compressive strength (MPa) & $138 \pm 8$ & $255 \pm 9$ & $164 \pm 11$ & $82 \pm 2$ \\
\hline
\end{tabular}




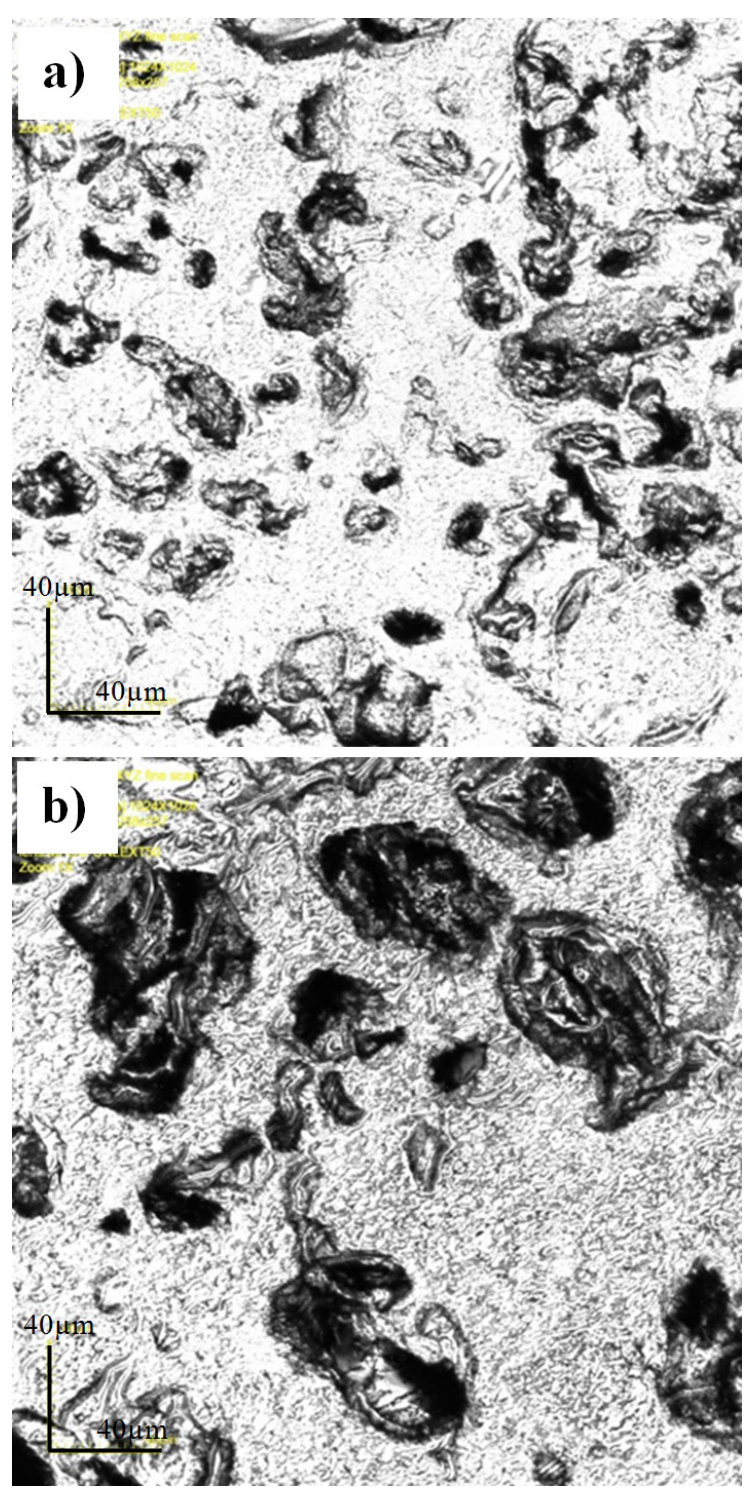

Figure 3. Optical micrographs of the red clay-based ceramics fired at $1250{ }^{\circ} \mathrm{C}$ : (a) micrograph of red clay-based body shaped with corn starch, and (b) micrograph of red clay-based body shaped with potato starch.

in pore diameters between the sintered samples explains the low compressive strength of fired sample shaped with potato starch. Moreover, the large measured porosity for the pressure-cooked samples shaped with potato starch can be attributed to its large initial particle size as well as its large swelling property as compared to other starches ${ }^{3}$.

\subsection{Shaping of large red clay-based ceramic prototypes}

To validate the applicability of the pressure-cooking process to ceramic shaping, large ceramic prototypes were fabricated with different shapes listed in Table 6. Correspondingly, different molds with large cavities made of the acetate film were assembled and joined with the use of double-sided tapes. Unfortunately during pressure cooking at the best heating time of twelve minutes, the casted ceramic

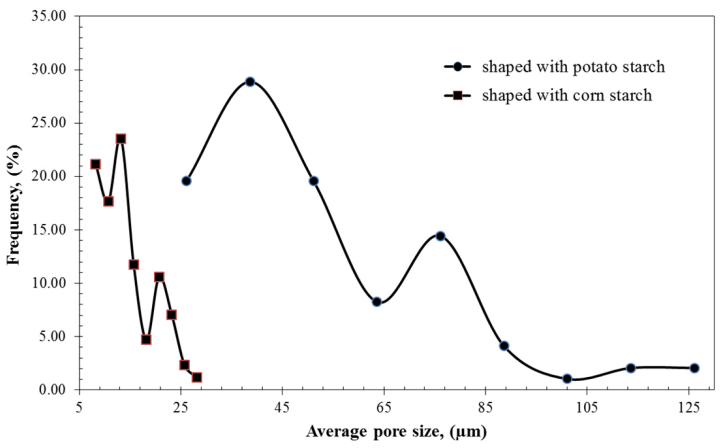

Figure 4. Distributions of average pore diameters for the red clay-based ceramics fired at $1250{ }^{\circ} \mathrm{C}$ : (a) red clay-based body shaped with corn starch, and (b) red clay-based body shaped with potato starch.

Table 6. Heating conditions of ceramic slurry loaded with starch for shaping large prototypes inside the pressure cooker.

\begin{tabular}{lcc}
\hline Prototype shapes & $\begin{array}{c}\text { Mass of slurry after } \\
\text { casting (grams) }\end{array}$ & $\begin{array}{c}\text { Pressure cooking } \\
\text { time (minutes) }\end{array}$ \\
\hline Pipe & 526.2 & 109 \\
Solid disc w/ hole & 115.6 & 24 \\
Solid disc & 112.5 & 23 \\
Solid cylinder & 57.9 & 12 \\
\hline
\end{tabular}

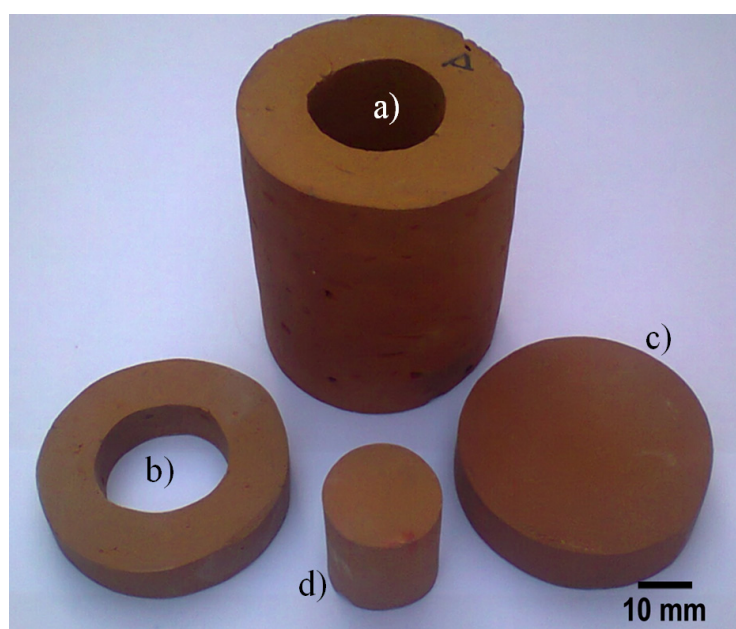

Figure 5. Pressure-cooked ceramic prototypes fired at $1250^{\circ} \mathrm{C}$. (a) Pipe, (b) Solid disc with hole, (c) Solid disc, and (d) Solid cylinder.

slurries with starch did not solidify. This implied that the heating inside the pressure cooker is a mass dependent and requires a longer pressure cooking time for the increased mass of the ceramic slurry. Thus, we proposed the following empirical Equation 3 as

$t_{p}=\frac{w_{p}}{w_{o}} t_{o}$

where $t_{p}$ is the pressure cooking time in minutes for any large mass of ceramic slurry denoted as $w_{p}$ in grams, and $t_{o}$ is the best cooking time of 12 minutes for a mass $\mathrm{w}_{\mathrm{o}}=57.9$ grams. 
The desired pressure cooking time can be conveniently computed with the use of the Equation 3 for any increased mass of starch-loaded ceramic slurry, which is casted into different shapes of the mold cavities listed on Table 6. It can be observed that the pressure cooking time increases from 12 minutes heating time as the mass of ceramic slurry increases. Subsequently, the large ceramic prototypes were successfully shaped, dried and fired at $1250{ }^{\circ} \mathrm{C}$ as shown in Figure 5.

\section{Conclusion}

The consolidation of red clay-based ceramic slurry through gelatinization of starch inside a domestic pressure cooker was successfully demonstrated. The gels strength of the ceramic suspensions containing starch heated under pressure cooker exhibited the same mechanism and cooking time of 12 minutes as the pure starch gel. Moreover, the gel strengths of the different type of starches were higher than the gelled starches heated conventionally. The physical characterizations disclosed that the physical properties of

\section{References}

1. Gregorova E and Pabst W. Process control and optimized preparation of porous alumina ceramics by starch consolidation casting. Journal of European Ceramic Society. 2011; 31:20732081. http://dx.doi.org/10.1016/j.jeurceramsoc.2011.05.018

2. Gregorova E, Pabst W and Bohacenko I. Characterization of different starch types for their application in ceramic processing. Journal of European Ceramic Society. 2006; 26:1301-1309. http://dx.doi.org/10.1016/j.jeurceramsoc.2005.02.015

3. Gregorova E, Zivcova Z and Pabst W. Starch as a poreforming and body-forming agent in ceramic technology. Starch/Stärke. 2009; 61:495-502. http://dx.doi.org/10.1002/ star.200900138

4. Gregorova E, Zivcova Z, Pabst W, Stitina J and Keuper M. Rheology of ceramic suspensions with organic or biopolymeric gelling additives part III: Suspensions with starch. CeramicsSilikaty. 2008; 52:250-259.

5. Almeida FA, Botelho EC, Melo FCL, Campos TMB and Thim GP. Influence of cassava starch content and sintering temperature on the alumina consolidation technique. Journal of European Ceramic Society. 2009; 29:1587-1594. http://dx.doi. org/10.1016/j.jeurceramsoc.2008.10.006

6. Talou MH and Camerucci MA. Two alternative routes for starch consolidation of mullite green bodies. Journal of European Ceramic Society. 2010; 30:2881-2887. http://dx.doi. org/10.1016/j.jeurceramsoc.2010.06.001

7. Talou MH, Villar MA, Camerucci MA and Moreno R. Rheology of aqueous mullite-starch suspensions. Journal of European Ceramic Society. 2011; 31:1563-1571. http://dx.doi. org/10.1016/j.jeurceramsoc.2011.03.031

8. Sandoval ML, Camerucci MA and Tomba Martinez AG. Hightemperature mechanical behavior of cordierite-based porous ceramics prepared by modified cassava starch thermogelation, Journal of Materials Science. 2012; 47:8013-8021. http:// dx.doi.org/10.1007/s10853-012-6691-9

9. Sandoval ML, Pucheu MA, Talou MH, Tomba Martinez AG and Camerucci MA. Mechanical evaluation of cordierite precursor green bodies obtained by starch thermogelling. pressure-cooked ceramics were dependent on the types of starch used when compared to conventional counterpart. Specifically, the fired ceramic samples shaped with corn starch inside the pressure cooker exhibited better physical properties, in terms of compressive strength and porosity, than the conventional counterpart. The physical properties of the fired samples shaped with potato starch inside the oven and pressure cooker were less satisfactory than samples shaped with corn starch, due to the presence of large pores that contribute to a high porosity. Subsequently, the shaping of large ceramic prototypes is possible using the calculated heating time based on the best pressure cooking conditions.

\section{Acknowledgements}

The MSU-Iligan Institute of Technology (MSU-IIT) is gratefully acknowledged for allowing us to publish the content of this study. Thanks are also due to Mrs. Nanette M. Abatayo our laboratory technician, who was exceedingly patient and committed in helping us during our laboratory activities.

Journal of European Ceramic Society. 2009; 29:3307-3317. http://dx.doi.org/10.1016/j.jeurceramsoc.2009.07.008

10. Menchavez RL and Intong LAS. Red clay-based porous ceramic with pores created by yeast-based foaming technique. Journal of Materials Science. 2010; 45:6511-6520. http:// dx.doi.org/10.1007/s10853-010-4740-9

11. Choi S and Kerr WL. Swelling characteristics of native and chemically modified wheat starches as a function of heating temperature and time. Starch/Stärke. 2004; 56:181-189. http:// dx.doi.org/10.1002/star.200300233

12. VermeylenR, GoderisB, ReynaersHandDelcourJA. Amylopectin molecular structure reflected in macromolecular organization of granular starch. Biomacromolecules. 2004;5:1775-1786. PMid:15360287. http://dx.doi.org/10.1021/bm0499132

13. Daniels DR and Donald AM. An improved model for analyzing the small angle X-ray scattering of starch granules. Biopolymers. 2003; 69:165-175. PMid:12767120. http://dx.doi. org/10.1002/bip.10341

14. Tang $\mathrm{H}$. and Hills BP. Use of ${ }^{13} \mathrm{C}$ MAS NMR to study domain structure and dynamics of polysaccharides in the native starch granules. Biomacromolecules. 2003;4:1269-1276. PMid:12959594. http://dx.doi.org/10.1021/bm0340772

15. Singhal RS, Pandit AB, Joshi JB, Patel SB, Danao SP, Shinde YH, Gudekar AS, Bineesh NP and Tarade KM. Development of Efficient Designs of Cooking Systems. III. Kinetics of Cooking and Quality of Cooked Food, Including Nutrients, Anti-Nutrients, Taste, and Flavor. Industrial Engineering and Chemical Research. 2012; 51:1923-1937. http://dx.doi. org/10.1021/ie202596d

16. Galleano M, Boveris A and Puntarulo S. Understanding the Clausius-Clapeyron equation by employing an easily adaptable pressure cooker. Journal of Chemical Education. 2008; 85:276-278. http://dx.doi.org/10.1021/ ed085p276

17. Rocca-Polimeni R, Flick D and Vasseur J. A model of heat and mass transfer inside a pressure cooker. Journal of Food Engineering. 2011; 107:393-404. http://dx.doi.org/10.1016/j. jfoodeng.2011.06.022 
18. Ming XC, Changxi S and Weizhou H. Rapid-processing procedure for heat polymerization of polymethyl methacrylate in a pressure cooker with automatic controls. The Journal of Prosthetic Dentistry. 1996; 76:445-447. http://dx.doi. org/10.1016/S0022-3913(96)90552-1

19. Undurwade $\mathrm{JH}$ and Sidhaye AB. Curing acrylic resin in a domestic pressure cooker: a study of residual monomer content. Quintessence International. 1989; 20:123-129. PMid:2762502.

20. Yau WFE, Cheng YY, Clark RKF and Chow TW. Pressure and temperature changes in heat-cured acrylic resin during processing. Dental Material. 2002; 18:622-629. http://dx.doi. org/10.1016/S0109-5641(01)00092-6

21. Martin-Marquez J, Ma Rincon J and Romero M. Effect of firing temperature on sintering of porcelain stoneware tiles. Ceramics International. 2008; 34:1867-1873. http://dx.doi.org/10.1016/j. ceramint.2007.06.006

22. Noranizan MA, Dzulkifly MH and Russly AR. Effect of heat treatment on the physico-chemical properties of starch from different botanical sources. International Food Research Journal. 2010;17:127-135.

23. Sagum R and Arcot J. Effect of domestic processing methods on the starch, non-starch polysaccharides and in vitro starch and protein digestibility of three varieties of rice with varying levels of amylose. Food Chemistry. 2000;70:107-111. http:// dx.doi.org/10.1016/S0308-8146(00)00041-8

24. Morgan WL and Vaughn NL. Starch Viscosity or Strength. Industrial and Engineering Chemistry. 1943;35:233-238. http://dx.doi.org/10.1021/ie50398a027

25. Li Y, Shoemaker CF, Ma J, Jin Moon K and Zhong F. Structureviscosity relationships for starches from different rice varieties during heating. Food Chemistry. 2008; 106:1105-1112. http:// dx.doi.org/10.1016/j.foodchem.2007.07.039

26. Srichuwong S, Sunarti TC, Mishima T, Isono N and Hisamatsu M. Starches from different botanical sources II: Contribution of starch structure to swelling and pasting properties. Carbohydrate Polymers. 2005; 62:25-34. http://dx.doi. org/10.1016/j.carbpol.2005.07.003

27. Ratnayake WS and Jackson DS. Gelatinization and Solubility of Corn Starch during Heating in Excess Water: New Insights. Journal of Agricultural and Food Chemistry. 2006; 54:37123716. PMid:19127749. http://dx.doi.org/10.1021/jf0529114

28. Srikaeo K, Furst JE, Ashton JF and Hosken RW. Microstructural changes of starch in cooked wheat grains as affected by cooking temperatures and times. LWT. 2006;39:528-533. http://dx.doi. org/10.1016/j.lwt.2005.04.004

29. Jing-ming L and Sen-lin Z. Scanning Electron Microscope Study on gelatinization of starch granules in excess water. Starch/Stärke. 1990;42:96-98. http://dx.doi.org/10.1002/ star. 19900420305
30. Charles AL, Chang YH, Ko WC, Sriroth K and Huang TC. Influence of Amylopectin Structure and Amylose Content on the Gelling Properties of Five Cultivars of Cassava Starches. Journal of Agricultural and Food Chemistry. 2005; 53:27172725. PMid:15796616. http://dx.doi.org/10.1021/jf048376+

31. Tester RF and Morrison, WR. Swelling and gelatinization of cereal starches. I. Effects of amylopectin, amylose, and lipids. Cereal Chemistry. 1990; 67:551-557.

32. Kyaw ZY, Cheow CS, Yu SY and Dzulkifly MH. The effect of pressure cooking on the microstructure and expansion of fish cracker ('Keropok'). Journal of Food Quality. 2001; 24:181194. http://dx.doi.org/10.1111/j.1745-4557.2001.tb00601.x

33. Cheng X, McCoy JH, Israelachvili JN and Cohen I. Imaging the microscopic structure of shear thinning and thickening colloidal suspensions. Science. 2011; 333:1276-1279. PMid:21885778. http://dx.doi.org/10.1126/science.1207032

34. Ochotorena ZL. Chemical analysis of clay resources of Iligan City and Lanao del Norte. The Technician. 1986; V:11-38.

35. Tateyama H, Scales PJ, Ooi M, Nishimura S, Rees K and Healy TW. X-ray diffraction and rheology study of highly ordered clay platelet alignment in aqueous solutions of sodium tripolyphosphate. Langmuir. 1997; 13:2440-2446. http:// dx.doi.org/10.1021/la960995s

36. Liu Q, Zhang Y and Laskowski JS. The adsorption of polysaccharides onto mineral surfaces: an acid/base interaction. International Journal of Mineral Processing. 2000; 60:229245. http://dx.doi.org/10.1016/S0301-7516(00)00018-1

37. Weissenborn PK. Behaviour of amylopectin and amylose components of starch in the selective flocculation of ultrafine iron ore. International Journal of Mineral Processing. 1996; 47:197-211. http://dx.doi.org/10.1016/03017516(95)00096-8

38. Aggarwal P and Dollimore D. The combustion of starch, cellulose and cationically modified products of these compounds investigated using thermal analysis. Thermochimica Acta. 1997; 91:65-72. http://dx.doi.org/10.1016/S00406031(96)03103-6

39. Cuadros J, Delgado A, Cardente A, Reyes E and Linares J. Kaolinite/montmorillonite resembles beidellite. Clays and Clay Mineral. 1994; 42:643-651. http://dx.doi.org/10.1346/ CCMN.1994.0420517

40. Zhiqiang L, Xiao-su Y and Yi F. Effect of bound water on thermal behaviours of native starch, amylose and amylopectin. Starch/Starke. 1999; 51:406-410. http://dx.doi. org/10.1002/(SICI)1521-379X(199912)51:11/12<406::AIDSTAR406>3.0.CO;2-K

41. Liu X, Wang Y, Yu L, Tong Z, Chen L, Liu H and Li X. Thermal degradation and stability of starch under different processing conditions. Starch/Starke. 2013; 65:48-60. 